\title{
A novel and robust recombinant Pichia pastoris yeast whole cell biocatalyst with intracellular overexpression of a Thermomyces lanuginosus lipase: Preparation, characterization and application in biodiesel production
}

\author{
Jinyong Yan*, Xianliang Zheng, Shengying Li* \\ Key Laboratory of Biofuels and Shandong Provincial Key Laboratory of Energy Genetics, Qingdao Institute of Bioenergy and Bioprocess Technology, \\ Chinese Academy of Sciences, 189 Songling Road, Qingdao, Shandong 266101, China
}

\section{H I G H L I G H T S}

- A novel and robust Pichia pastoris yeast whole cell biocatalyst is reported.

- The short chain alcohol tolerant and easily scalable biocatalyst is developed.

- The biocatalyst gives improved biodiesel yield and productivity than Lipozyme TLIM.

\section{A R T I C L E I N F O}

\section{Article history:}

Received 2 September 2013

Received in revised form 8 October 2013

Accepted 11 October 2013

Available online 18 October 2013

\section{Keywords:}

Lipase

Whole cell catalyst

Pichia pastoris

Biodiesel

Waste cooking oils

\begin{abstract}
A B S T R A C T
A novel and robust recombinant Pichia pastoris yeast whole cell catalyst (WCC) with functional intracellular expression of Thermomyces lanuginosus lipase (Tll) was constructed and characterized for biodiesel production from waste cooking oils. This permeabilized WCC was able to convert waste cooking oils to biodiesel with $82 \%$ yield within $84 \mathrm{~h}$ at $6 \%$ dosage whole cells. The WCC showed two fold catalytic activity of $0.73 \mathrm{U} / \mathrm{mg}$ DCW compared to its commercial counterpart Lipozyme TLIM (immobilized Tll). Short chain alcohol tolerance of this WCC was significantly improved compared to Lipozyme TLIM. This beneficial property enabled it to catalyze biodiesel production efficiently with one step addition of methanol. The reusability of this biocatalyst retained $78 \%$ activity after three batch cycles. This easily prepared and cost-effective WCC showed better catalytic performance than Lipozyme TLIM with respect to biodiesel yield and productivity, thus suggesting a promising cost-effective biocatalyst for biodiesel production. (c) 2013 Elsevier Ltd. All rights reserved.
\end{abstract}

\section{Introduction}

The fatty acid methyl esters (FAMEs) and fatty acid ethyl esters (FAEEs) produced by transesterification of triglycerides from vegetable oils and animal fats, known as biodiesel, have been receiving ever-increasing attentions because they are renewable and environment-friendly biofuels with excellent fuel properties (Tan et al., 2010). The cost of biodiesel production is mainly dependent on the price of oil feedstocks. The high price of edible oils makes their conversion into biodiesel economically infeasible (Yan et al., 2011). Instead, the low cost waste cooking oils are a promising

Abbreviations: WCCs, whole cell catalysts; FAMEs, fatty acid methyl esters; FAEEs, fatty acid ethyl esters; FFAs, free fatty acids; DCW, dry cell weight; BSPs, biomass support particles.

* Corresponding authors. Tel.: +86 532 80662675; fax: +86 53280662778 (J. Yan).

E-mail addresses: yjiny@126.com (J. Yan), lishengying@qibebt.ac.cn (S. Li). alternative to edible oils for biodiesel production despite of their low quality.

For common biodiesel production using refined vegetable oils as feedstock, alkaline catalysis has been proven much more efficient and cost-effective than acid catalysis. However, the high content free fatty acids (FFAs) present in waste cooking oils need to be reduced by acid-catalyzed esterification prior to base-catalyzed transesterification. Otherwise, the soap formation between FFAs and bases would deactivate the alkali catalysts to hamper the transesterification (Lam et al., 2010). In addition, the use of both acids and bases could lead to a number of significant problems such as reactor corrosion, complex neutralization, and environmental pollution (Lam et al., 2010). By comparison, some lipases are able to efficiently catalyze esterification of FFAs and transesterification of triglycerides simultaneously in presence of methanol or ethanol (Yan et al., 2011; Adachi et al., 2013a,b), thus representing suitable biocatalysts for generation of biodiesel from waste 
cooking oils. Moreover, other advantages related to enzymatic biodiesel production include mild reaction conditions, less environment impacts and easy separation of byproduct glycerol (Yan et al., 2011).

Apart from these advantageous catalytic properties of lipases, the cost of lipases is another important factor to be taken into account with respect to economic biodiesel production. To date, three major types of lipase biocatalysts, including free enzymes, immobilized enzymes and whole cell catalysts (WCCs) have been employed for synthesis of biodiesel. Free enzymes are unstable, difficult to be reused and hence expensive. Immobilized lipase preparations have been widely used in many industrial processes including biodiesel production. Various immobilization carriers and immobilization technologies have offered opportunities in tuning enzyme properties such as stability, activity and selectivity, as well as high volumetric loading (Barbosa et al., 2013; Rodrigues et al., 2013; Verma et al., 2013). However, they are expensive since their preparation requires costly steps of enzyme extraction and immobilization (Tan et al., 2010). To achieve an applicable immobilized lipase product, a lot of work for seeking optimal immobilization carriers and immobilization conditions is necessary. These complicate the use of immobilized lipases for industrial production of biodiesel. In comparison, the lipase WCC may provide the best solution to reduce the biocatalyst cost because its simple preparation does not require any purification and immobilization steps (Fukuda et al., 2008). Similar to immobilized enzymes, the stability and reusability of lipases in the form of WCC can be significantly improved compared to free enzymes (Takaya et al., 2011; Koda et al., 2010). Taken together, the WCC lipase represents a promising biocatalyst for biodiesel production in a cost-effective manner.

So far, three major forms of WCCs have been applied in biodiesel production. First, the fungal cells of Rhizopus spp with cellbound lipases represent examples of natural WCCs (Li et al., 2007; He et al., 2008). Specifically, Rhizopus oryzae and Rhizopus chinensis were found to secrete a portion of lipases into extracellular space, while retain the rest as the intracellular membranebound form. Apparently, not all lipases exist as WCC in this case, and additional immobilization with biomass support particles (BSPs) or glutaraldehyde is often preferred for improvement of their stability and activity (Ban et al., 2002; Xiao et al., 2011).

Second, display of lipases on the surface of yeast cells including Pichia pastoris and Saccharomyces cerevisiae via expression of genetically fused enzyme-anchor proteins has been developed as another type of WCC for biodiesel production (Matsumoto et al., 2002; Huang et al., 2012). These yeast cells with surface displayed lipases are more substrate accessible compared to intracellular enzymes. However, the expression level and enzymatic activity of the anchored lipases are generally low. In addition, establishment of the compatible relationship among anchor protein, target lipase and host cell is not easy work.

Third, the strategy of preparing lipase WCCs for biodiesel production by intracellular overexpression of lipases inside heterologous host has emerged recently. The investigations were carried out in Escherichia coli (Yan et al., 2012; Li et al., 2012; Gao et al., 2009) and S. cerevisiae (Matsumoto et al., 2001). Surprisingly, this strategy has not yet been extended to the yeast of $P$. pastoris, which can achieve higher cell density, and a greater expression level of functional heterologous enzymes due to less hyper-glycosylation than S. cerevisiae yeast (Patrick et al., 2005). It is able to accumulate large amounts of intracellular enzymes to the level as high as that of excreted proteins (Patrick et al., 2005), thereby becoming a "selfimmobilized" biocatalyst that retains almost all active enzymes inside the cells.

Thermomyces lanuginosus lipase (Tll) has been well known as a versatile biocatalyst in various industrial areas including biodiesel production, modification of oils, chiral resolution of racemic compounds and others (Fernandez-Lafuente, 2010). Thus, in the present work, we selected this useful enzyme to exploit its new preparation as the form of WCC, and applied it into biodiesel production. Specifically, a recombinant $P$. pastoris yeast strain with intracellular expression of $T$. lanuginosus lipase was constructed for preparation of a novel WCC. The organic solvent tolerance and thermostability of this WCC were characterized. Its ability of converting waste cooking oils into biodiesel was studied. To the best of our knowledge, this is the first example of using recombinant $P$. pastoris yeast to functionally overexpress intracellular lipases as a robust WCC for biodiesel production.

\section{Methods}

\subsection{Plasmid, strains, media and reagents}

The plasmid pPICZA and yeast strain $P$. pastoris $\mathrm{X}-33$ were purchased from Invitrogen. E. coli DH5 $\alpha$ was reserved in our laboratory. Pretreated waste cooking oils (a mixture of waste oils from kitchen sewer) with 19\% FFA content were kindly donated by Lvming Environmental Protection Technology Co., Ltd. (Shanghai, China), and their main properties were as follows: saponification value of $366 \mathrm{mg} \mathrm{KOH} / \mathrm{g}$, acid value of $170 \mathrm{mg} \mathrm{KOH} / \mathrm{g}$, density of $0.89 \mathrm{~g} / \mathrm{cm}^{3}$, water content of $0.1 \%$, and mechanical impurities of $0.4 \%$. Immobilized enzyme Lipozyme TLIM was the product of Novozymes. Standard FAME mix (equal mole of methyl palmitate, methyl stearate, methyl oleate, methyl linoleate, and methyl linolenate) and internal standard ( $n$-hexadecane) were purchased from Sigma-Aldrich. All used restricted enzymes and genetic manipulation kits were supplied by Takara. The antibotic zeocin was bought from Solarbio Science \& Technology Co., Ltd (Beijing, China). Yeast nitrogen base (YNB), yeast extract, tryptone and biotin were from Oxoid. Organic solvents and other reagents were analytical grade.

Recipes for used media were as follows: YPDS medium: 2\% tryptone, $1 \%$ yeast extract, $1 \%$ dextrose, $1 \mathrm{M}$ sorbitol, $1.5 \%$ agar, supplemented with certain concentration of zeocin. BMGY medium: $2 \%$ tryptone, $1 \%$ yeast extract, $100 \mathrm{mM}$ potassium phosphate buffer, $\mathrm{pH} 7.0,1.34 \%$ YNB, 0.4 ppm biotin, 1\% (v/v) glycerol. BMMY medium: $2 \%$ tryptone, $1 \%$ yeast extract, $100 \mathrm{mM}$ potassium phosphate buffer, pH 7.0, 1.34\% YNB, 0.4 ppm biotin, 1\% (v/v) methanol. Low salt LB medium: $1 \%$ tryptone, $0.5 \%$ yeast extract, $0.5 \% \mathrm{NaCl}$, supplemented with $25 \mu \mathrm{g} / \mathrm{ml}$ zeocin if required, $1.5 \%$ agar powder was added for agar plate preparation.

\subsection{Construction of plasmid and recombinant strain}

The codon optimized tll gene (Genbank Accession No. AF054513.1) based on the codon bias of P. pastoris (Supporting information, Fig. S1) was synthesized by GenScript. Using the synthetic gene as template, the tll fragment with its own signal peptide removed and an ATG start codon added before the mature lipase sequence was amplified by PCR with primers as follow: forward, 5'-CCGGAATTCATGTCACCTATCAGAAGAGAAGTTTCAC-3' (the underlined nucleotides indicate the EcoRI restriction site); reverse, 5'-AAGGAAAAAAGCGGCCGCCTACAAGCAAGTTCCGATAAGACC-3' (the underlined bases denote the NotI cutting site). Next, the EcoRI and NotI double digested tll fragment was ligated into the EcoRI/ NotI pretreated plasmid pPICZA. The resulted plasmid was transformed into $E$. coli DH5 $\alpha$ competent cells. Transformants grown on low salt LB medium containing $25 \mu \mathrm{g} / \mathrm{ml}$ zeocin was employed for preparation of pPICZA-tll, whose sequence was confirmed by DNA sequencing at Sangon, Shanghai.

For yeast transformation, pPICZA-tll was linearized by SacI and transformed into competent cells of $P$. pastoris $\mathrm{X}-33$ via electroporation under the following conditions: $0.2 \mathrm{~cm}$ cuvette, $1500 \mathrm{~V}$, 
$200 \Omega, 25 \mu \mathrm{F}$. The positive transformants harboring chromosomal integration of Tll expression cassettes were preliminarily selected on YPDS plates containing $100 \mu \mathrm{g} / \mathrm{ml}$ zeocin. Multi-copy integrated recombinants were further screened on YPDS plates supplemented with gradually increased concentration of zeocin $(500-2000 \mu \mathrm{g} / \mathrm{ml})$

\subsection{Intracellular expression of recombinant Tll lipase}

A single colony of $P$. pastoris containing multi-copy Tll expression cassettes was inoculated into $5 \mathrm{ml}$ BMGY medium and cultured at $28^{\circ} \mathrm{C}, 250 \mathrm{rpm}$, for $24 \mathrm{~h}$. This seed culture was transferred to $50 \mathrm{ml}$ BMGY medium in a $500 \mathrm{ml}$ baffled flask and grown until $\mathrm{OD}_{600}$ reaching $4-6$. The cells were sterilely collected by centrifugation and re-suspended in a 21 baffled flask by $400 \mathrm{ml}$ pre-loaded fresh BMMY medium. Subsequently, 1\% (v/v) methanol was added into culture every $24 \mathrm{~h}$ for induction of lipase expression. The strain harboring empty vector pPICZA was subject to the same manipulation as control for expression analysis.

\subsection{Determination of cell density and catalytic activity}

At designated time intervals, $0.5 \mathrm{ml}$ aliquots of induced cell culture in BMMY medium were withdrawn for determination of cell density by measuring $\mathrm{OD}_{600}$. Yeast cells with intracellular expression of Tll were collected from $5 \mathrm{ml}$ culture by centrifugation, re-suspended and washed twice with $0.85 \%(w / v) \mathrm{NaCl}$ solution, re-centrifuged, and used as untreated whole cell biocatalysts. Following the previously established protocol (Yan et al., 2007) with slight modifications, the hydrolytic reactions were conducted using emulsified olive oil as substrate. Emulsified olive oil was prepared by homogenizing a mixture of olive oil and $2 \%$ polyvinyl alcohol solution $(1: 3, v / v)$ using homogenizer at $6000 \mathrm{rpm}$ for $10 \mathrm{~min}$. The reaction mixture contained $5 \mathrm{ml}$ of $50 \mathrm{mM}$ Tris- $\mathrm{HCl}$ buffer ( $\mathrm{pH} 8.0$ ), $4 \mathrm{ml}$ of emulsified olive oil as substrate, and $50 \mathrm{mg}$ whole cells or Lipozyme TLIM as catalysts. The hydrolysis reactions were carried out at $40^{\circ} \mathrm{C}$ and $\mathrm{pH}$ 8.0 for $10 \mathrm{~min}$, and stopped by addition of $15 \mathrm{ml}$ ethanol. Activity was determined titrimetrically using $50 \mathrm{mM} \mathrm{NaOH}$ as titrant. The same amount of whole cell lipases was inactivated by boiling at $100{ }^{\circ} \mathrm{C}$ for $1 \mathrm{~h}$ and used as control. One unit of lipase activity was defined as the amount of enzyme that hydrolyzes olive oils to form $1 \mu \mathrm{mol}$ free fatty acid per minute under testing conditions. The specific activity was calculated as units of enzyme activity possessed by one milligram of dry cell weight (U/mg DCW). DCW was determined by oven drying wet cells to constant weight at $60{ }^{\circ} \mathrm{C}$. With respect to the commercial immobilized enzyme Lipozyme TLIM, its activity was defined as units of enzyme activity held by one milligram of solid catalysts. Unless otherwise specified, all quantitative experiments in this study were performed in duplicate. $P<0.05$ indicated statistical significance $(*)$.

\subsection{Characterization of organic solvent tolerance and thermostability}

The untreated yeast whole cell biocatalysts were incubated with $25 \%(\mathrm{v} / \mathrm{v})$ short chain alcohol (methanol, ethanol or isopropyl alcohol) at room temperature for $30 \mathrm{~min}$ or heated at $50-70{ }^{\circ} \mathrm{C}$ for $30 \mathrm{~min}$. Organic solvent tolerance and thermostability were characterized by determining residual activity of whole cell catalysts after alcohol treatment and heating, respectively, relative to that of untreated cells. Similarly, these properties of Lipozyme TLIM were determined under the same conditions.

\subsection{Permeabilization of yeast whole cells}

Freeze drying permeabilization was conducted by freezing yeast cells at $-80^{\circ} \mathrm{C}$ for $12 \mathrm{~h}$ and drying with lyophilizer for $48 \mathrm{~h}$. Isopropyl alcohol treatment coupled to freeze-drying permeabilization was performed by incubation of cells in 25\% isopropyl alcohol for $30 \mathrm{~min}$ at $4{ }^{\circ} \mathrm{C}$ and followed by freeze-drying.

\subsection{Biotransformation of waste cooking oils into biodiesel}

Reaction mixture containing $2 \mathrm{~g}$ waste cooking oils and total $300 \mu \mathrm{l}$ methanol (molar ratio of $1: 4$ ) was emulsified with $5 \%$ (wt\% relative to oil) polyvinyl alcohol solution and placed in a conical flask with stopper. 6\% (wt\% relative to oil) whole cell lipase or $12 \%$ (wt\% relative to oil) immobilized lipase Lipozyme TLIM were added to initiate the biotransformation. One third of total amount of methanol was added at 0,24 and $48 \mathrm{~h}(0,12$ and $24 \mathrm{~h}$ for Lipozyme TLIM). To investigate the methanol tolerance of biocatalysts, all methanol was added at once at $0 \mathrm{~h}$ to reaction mixture. Reactions were carried out at $40^{\circ} \mathrm{C}, 250 \mathrm{rpm}$ with a heating magnetic stirring system. The whole cells harboring empty vector were subject to the same preparation procedure and reaction conditions as control.

To evaluate the reusability of biocatalysts, the yeast whole cell catalysts were rescued by centrifugation at $6000 \times \mathrm{g}$ for $5 \mathrm{~min}$ after every batch reaction. Upon washing with tert-butanol and drying, the recovered biocatalysts were used for new batch reaction under the same conditions. The operational stability in each batch cycle was characterized by measuring the relative biodiesel yield compared to that of the first reaction.

\subsection{Identification of FAMEs}

The aliquots taken from reaction mixture at certain time points were mixed with $0.1 \mathrm{ml}$ deionized water and centrifuged for $10 \mathrm{~min}$ at $11,000 \times \mathrm{g}$. Then, $10 \mu \mathrm{l}$ top layer was mixed with $990 \mu \mathrm{l}$ $n$-hexane containing $1 \mathrm{mM}$ internal standard of $n$-hexadecane as the testing sample for GC analysis. Briefly, $1 \mu \mathrm{l}$ sample was injected into Agilent 7890A GC system equipped with flame-ionization detector and a capillary column (INNOWAX, Agilent, $30 \mathrm{~m} \times 0.25 \mathrm{~mm} \times 0.25 \mu \mathrm{m}$ ) for FAME analysis. The column temperature was increased from 150 to $260^{\circ} \mathrm{C}$ at $5{ }^{\circ} \mathrm{C} / \mathrm{min}$, and kept at $260{ }^{\circ} \mathrm{C}$ for $5 \mathrm{~min}$. The temperatures of injector and detector were set at 240 and $280^{\circ} \mathrm{C}$, respectively. The produced FAMEs were identified through comparison with corresponding authentic standards regarding their retention time. Quantitative analysis of FAMEs was performed as described previously (Li et al., 2012) using internal standard $n$-hexadecane as reference.

\section{Results and discussion}

\subsection{Recombinant strain construction and whole cell biocatalyst preparation}

The recombinant $P$. pastoris yeast strain of $\mathrm{X}-33\left(\mathrm{Mut}^{+}\right)$with intracellular overexpression of Tll was constructed through multiple chromosomal integration of the expression cassette consisting of the tll gene with signal peptide sequence removed and the selectable zeocin resistance gene $\left(\mathrm{zeo}^{\mathrm{r}}\right.$ ) onto the AOX1 (alcohol oxidase 1) locus of host genome. This was achieved by multiple single crossover events occurred at the $5^{\prime}$ AOX 1 promoter region or the AOX1 transcription terminator region via homologous recombination between linearized vector and host genome (Supporting information, Fig. S2). Positive transformants harboring multiple integrated Tll expression cassettes were stepwise 
screened on YPDS plates supplemented with gradually increased concentration (500-2000 $\mu \mathrm{g} / \mathrm{ml}$ ) of zeocin.

A recombinant $P$. pastoris yeast strain containing multi-copy Tll$z o^{r}$ gene cassettes demonstrated by good resistance to $2000 \mu \mathrm{g} /$ $\mathrm{ml}$ of zeocin was selected for lipase fermentation in shaking flask. The general procedure for expression of recombinant lipases in Pichia yeast consists of two stages: (1) the biomass accumulation in BMGY medium to avoid the potential toxicity resulted from heterogenous protein and/or the expression inducer methanol; (2) the lipase production after the cell density reached $\mathrm{OD}_{600}$ of $4-6$ in BMGY medium, at which the yeast cells were transferred from BMGY to BMMY medium for further biomass production and lipase expression. As shown in Fig. 1A, the peak cell density reached $\mathrm{OD}_{600}$ of 52 at $48 \mathrm{~h}$ after methanol induction. The high cell density is a significant advantage with regard to cost-effective preparation of biocatalysts at large scale. More importantly, the highest specific olive oil hydrolyzing activity of the whole cell Tll catalyst was determined to be $0.73 \mathrm{U} / \mathrm{mg}$ DCW, which is significantly higher than $0.37 \mathrm{U} / \mathrm{mg}$ solid catalyst of the commercially available immobilized Tll-Lipozyme TLIM (Fig. 1B). This strongly suggests that the yeast whole cells are likely to be a better "immobilizing carrier" for functional Tll enzymes than the poly acrylic resin used in Lipozyme TLIM. If further taking simpler and cheaper preparation into account, Tll WCC is a promising candidate to be developed into an industrial biocatalyst.

\subsection{Short chain alcohol tolerance of Tll WCC}

Intolerance of lipase enzymes toward short chain alcohols would limit their application in biodiesel production. To investigate whether Tll WCC is tolerant to short chain alcohols, methanol, ethanol and isopropyl alcohol $(25 \%, v / v)$ were used to pre-treat the yeast whole cells for $30 \mathrm{~min}$, and the residual activity of hydrolyzing olive oils was measured. Interestingly, the alcohol treated WCCs displayed higher activity than the untreated cells (Fig. 2A). In particular, a $45 \%$ improvement of activity was observed in the case of isopropyl alcohol treatment. These results are consistent with the previous study that alcohol treatment of S. cerevisiae cells enhanced the conversion rate of $S$-lactoylglutathione (Kondo et al., 2000). On the contrary, the short chain alcohol treatments have adverse effects on the commercial immobilized enzyme Lipozyme TLIM, which are in good agreement with a previous report (Martín and Otero, 2008).

The comprehensive effects imposed by short chain alcohol treatment could be categorized into three positive or negative aspects including (1) the polar microenvironment created by short chain alcohol for formation of essential water layer to stabilize the active enzymes (Rodrigues et al., 2013); (2) the role as cell permeabilizers, which facilitate substrates across yeast cell walls and cell membranes to improve substrate-enzyme interactions; and (3) the enzyme deactivation effect by short chain alcohol. It is particularly noteworthy that the intracellular environment of WCC is likely to be a significant factor for protecting inside lipase from deactivating alcohol and for maintaining active enzyme conformation. In contrast, the same alcohol treatment led to adverse effect on immobilized lipase Lipozyme TLIM, thus highlighting this significant advantage of WCC Tll over Lipozyme TLIM with respect to short chain alcohol tolerance.

\subsection{Thermal stability of Tll WCC}

Tll has been known as a thermophilic enzyme (Fernandez-Lafuente, 2010). To evaluate whether the form of biocatalyst alters the thermostability of Tll, the WCC activity to hydrolyze olive oils was measured at a range of high temperatures. Similar to Lipozyme TLIM, Tll WCC exhibited high thermal stability (Fig. 2B), retaining $97 \%$ and $89 \%$ of activity after incubation at 50 and $60{ }^{\circ} \mathrm{C}$ for $30 \mathrm{~min}$, respectively. Despite a significant loss of activity at $70{ }^{\circ} \mathrm{C}$, it was still more stable than Lipozyme TLIM.

\subsection{Biotransformation of waste cooking oils to biodiesel by Tll WCC}

Given that Tll WCC demonstrated significantly higher short chain alcohol tolerance than the immobilized enzyme Lipozyme TLIM, we expected that it should be a better biocatalyst in short chain alcohols involved in biodiesel production. Thus, using Lipozyme TLIM as reference, the activity of Tll WCC to transform waste cooking oils into FAMEs was assessed. As shown in Fig. 1B, Tll WCC showed the olive oil hydrolyzing activity of $0.73 \mathrm{U} / \mathrm{mg}$ DCW, which is almost two-fold that of Lipozyme TLIM $(0.37 \mathrm{U} / \mathrm{mg}$ catalyst). Therefore, the amount of immobilized lipase ( $12 \% \mathrm{wt})$ was doubled relative to WCC ( $6 \% \mathrm{wt}$ ) in order to apply the same level of enzymatic activity into biotransformation of waste cooking oils to biodiesel.

Unexpectedly, the maximal biodiesel yield of Tll WCC (44\% at 108 h, Fig. 3) turned out to be approximately $60 \%$ of that of Lipozyme TLIM (75\% at $48 \mathrm{~h}$ ). The reason could be limited substrate accessibility to intracellular lipases due to the shielding effect of yeast cell walls and cell membrances. Thus, permeabilization of yeast cells could promote mass transfer across these physical barriers to improve the catalytic performance of Tll WCC. To test this hypothesis, freeze-drying permeabilization was first attempted since it has been known as a simple but effective permeabilization method for improvement of biotransformation by $S$. cerevisiae
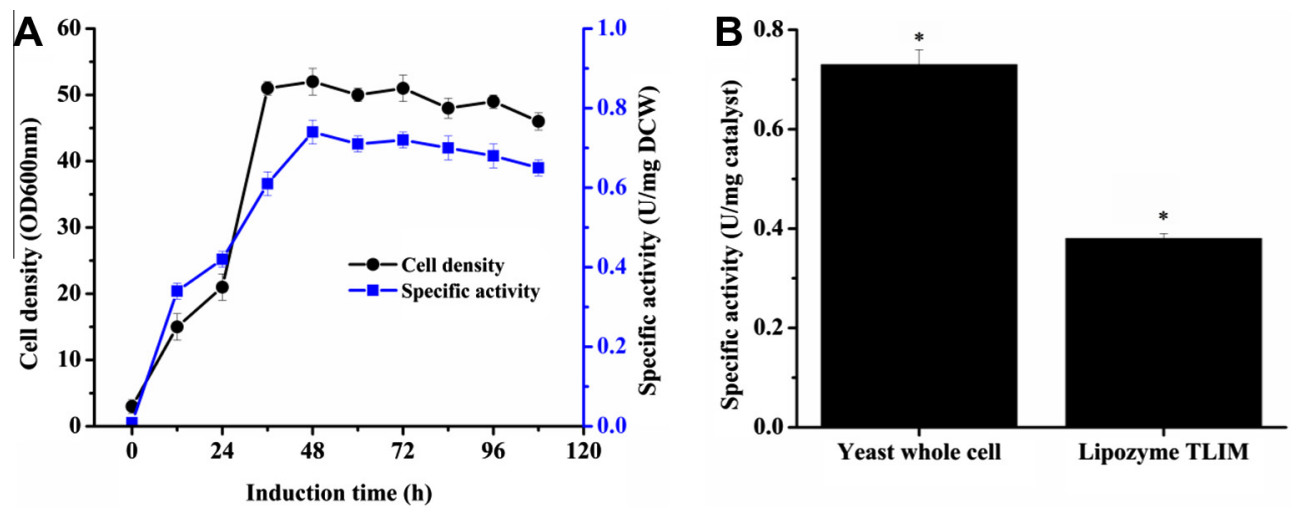

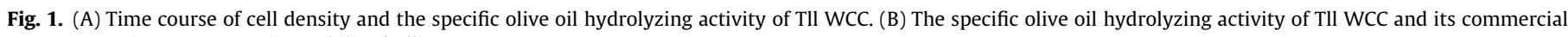
counterpart Lipozyme TLIM (immobilized Tll). 

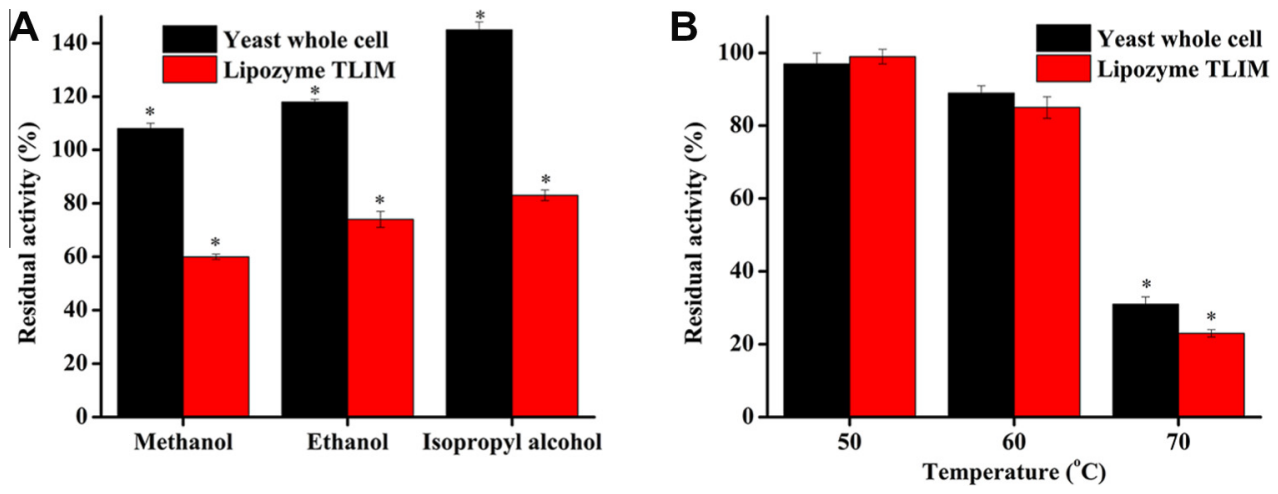

Fig. 2. Effects of short chain alcohols (A) and temperature (B) on Tll WCC and Lipozyme TLIM.

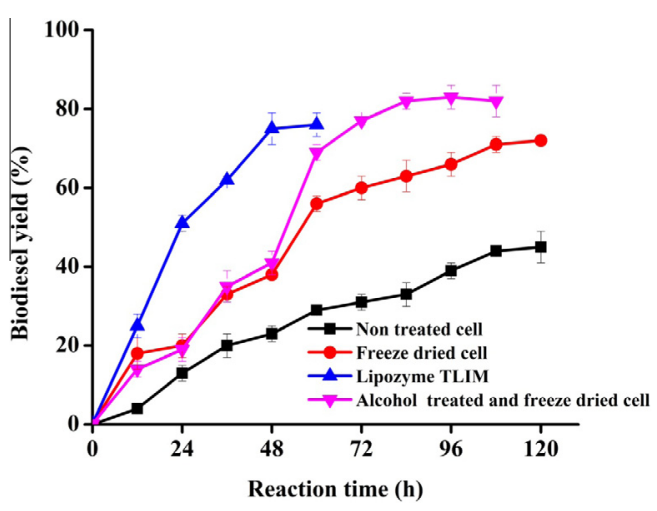

Fig. 3. Biodiesel production from waste cooking oils by variant forms of Tll.

yeast cells (Matsumoto et al., 2001). Using the freeze-dried Tll WCC, the highest biodiesel yield was increased to $71 \%$ at $108 \mathrm{~h}$. According to above described results (Fig. 2A), alcohol treatment is another effective method of permeabilization. Upon a combination of isopropyl alcohol (the best permeablizing alcohol among the tested short chain alcohols) treatment and freeze-drying, the maximal biodiesel yield of Tll WCC was further enhanced to $82 \%$ at $84 \mathrm{~h}$, which is higher than that of Lipozyme TLIM despite of longer reaction time.

It is evident that Lipozyme TLIM showed much higher initial catalytic rate than Tll WCC, consistent with the previous result from Matsumoto et al. This could be explained by more efficient mass transfer in immobilized Tll. After all, the permeabilization of WCC would take extra time. However, Tll WCC demonstrated higher biodiesel yield and biodiesel productivity (9.76\% yield/g catalyst.h) provided with additional reaction time of $36 \mathrm{~h}$ compared to Lipozyme TLIM (7.81\% yield/g catalyst.h). Importantly, it is much easier to prepare large amounts of Tll WCC by cultivation, cell harvesting, and permeabilization treatment.

Enzyme inactivation by methanol is one of central limitations in lipase mediated biodiesel production. Although stepwise addition of methanol has solved this problem to some extent (Li et al., 2007), one step addition of methanol is still preferred because it would simplify the process for practical application, especially at industrial scale. Thus, the compatibility of Tll WCC with one step addition of methanol was evaluated. Compared to Lipozyme TLIM, the yeast cells permeabilized by isopropyl alcohol treatment and freeze-drying displayed significantly higher biodiesel yield in the reaction with one step methanol

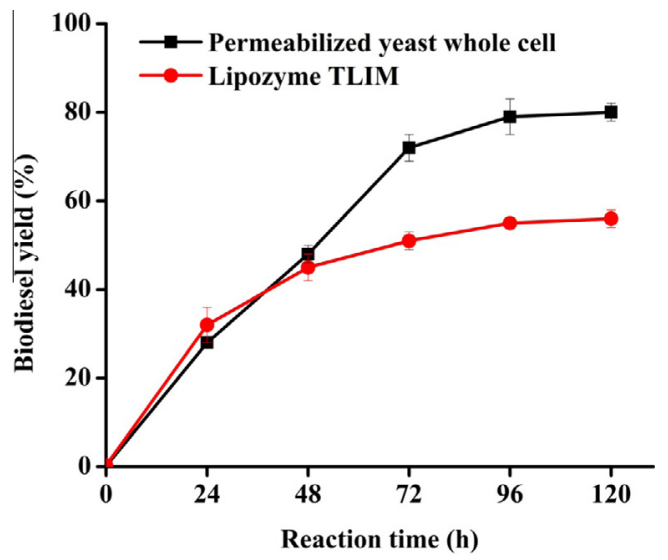

Fig. 4. Biodiesel production from waste cooking oils by Tll WCC and Lipozyme TLIM in the reaction with one step methanol addition.

addition (Fig. 4). This is likely due to its much better tolerance to methanol.

Taken together, Tll WCC is probably a better option for economic production of biodiesel from waste cooking oils than costly immobilized Lipozymes. However, immobilized lipases may still hold advantages in other applications such as chiral resolution of racemic compounds and synthesis of high value-added fine chemicals. Aiming to develop it into an applicable biocatalyst, the systematic optimization of parameters including catalyst dosage, substrate molar ratio, water content, reaction temperature and reaction time involved in biodiesel production is currently ongoing in our laboratory.

\subsection{Recyclable stability of Tll WCC and immobilized Lipozyme TLIM}

Biocatalysts with good recyclable stability further reduce the cost of biotransformation. The permeabilized Tll WCC by isopropyl alcohol treatment and freeze-drying was used to catalyze biodiesel synthesis in continuous batches. As result, Tll WCC retained more than $70 \%$ activity after three biotransformation cycles (Fig. 5), showing comparable reusability to Lipozyme TLIM. It is worth noting that no lipase activity was detected in the washing organic solvents, which indicates the yeast cell walls and/or cell membranes serve well as natural barriers to keep all biocatalysts inside cells. The similar activity loss of the two forms of Tll in recyclable batches might be attributed to gradual deactivation by methanol and various negative components in waste cooking oils such as metal ions and glue substances. 


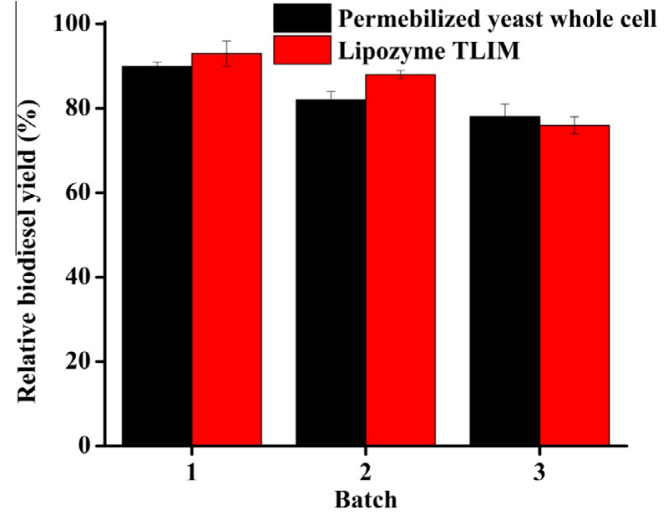

Fig. 5. Biodiesel production by Tll WCC and Lipozyme TLIM in batch cycles.

\section{Conclusion}

A novel and robust recombinant $P$. pastoris yeast whole cell biocatalyst with intracellular overexpression of Tll was developed for biodiesel production from waste cooking oils. The permeabilization of Tll WCC led to $82 \%$ biodiesel yield, and remained $78 \%$ activity after three batch cycles. It also efficiently catalyzed biodiesel production in the reaction with one step methanol addition. This catalytically efficient, thermostable, organic solvent tolerant, easily scalable, reusable, and cost-effective Tll WCC holds great potential for economic biodiesel production. The yeast whole cell biocatalytic system also establishes a new platform for lipase-associated biocatalysis and biotransformation processes.

\section{Acknowledgements}

This work was partially supported by funding from the National High Technology Research and Development Program of China (NO. SS2014AA091610) and "Recruitment Program of Global Experts, 2012" (S. Li). We are grateful to Ms. Wei Zhou at Lvming Environmental Protection Technology Co., Ltd. (Shanghai, China) for providing us with the waste cooking oils.

\section{Appendix A. Supplementary data}

Supplementary data associated with this article can be found, in the online version, at http://dx.doi.org/10.1016/j.biortech. 2013.10.037.

\section{References}

Adachi, D., Koh, F.H., Hama, S., Ogino, C., Kondo, A., 2013a. A robust whole-cell biocatalyst that introduces a thermo- and solvent-tolerant lipase into Aspergillus oryzae cells: characterization and application to enzymatic biodiesel production. Enzyme Microb. Technol. 52, 331-335.

Adachi, D., Hama, S., Nakashima, K., Bogaki, T., Ogino, C., Kondo, A., 2013b. Production of biodiesel from plant oil hydrolysates using an Aspergillus oryzae whole-cell biocatalyst highly expressing Candida antarctica lipase B. Bioresour. Technol. 135, 410-416.
Ban, K., Hama, S., Nishizuka, K., Kaieda, M., Matsumoto, T., Kondo, A., Noda, H., Fukuda, H., 2002. Repeated use of whole-cell biocatalysts immobilized within biomass support particles for biodiesel fuel production. J. Mol. Catal. B Enzym. 17, 157-165.

Barbosa, O., Torres, R., Ortiz, C., Berenguer-Murcia, A., Rodrigues, R.C.,FernandezLafuente, R., 2013. Heterofunctional supports in enzyme immobilization: from traditional immobilization protocols to opportunities in tuning enzyme properties. Biomacromolecules 14, 2433-2462.

Fernandez-Lafuente, R., 2010. Lipase from Thermomyces lanuginosus: uses and prospects as an industrial biocatalyst. J. Mol. Catal. B Enzym. 62, 197-212.

Fukuda, H., Hama, S., Tamalampudi, S., Noda, H., 2008. Whole-cell biocatalysts for biodiesel fuel production. Trends Biotechnol. 26, 668-673.

Gao, B., Su, E.Z., Lin, J.P., Jiang, Z.B., Ma, Y.S., Wei, D.Z., 2009. Development of recombinant Escherichia coli whole-cell biocatalyst expressing a novel alkaline lipase-coding gene from Proteus sp. for biodiesel production. J. Biotechnol. 139, 169-175.

He, Q., Xu, Y., Teng, Y., Wang, D., 2008. Biodiesel production catalyzed by whole-cell lipase from Rhizopus chinensis. Chin. J. Catal. 29, 41-46.se.

Huang, D.F., Han, S.Y., Han, Z.1., Lin, Y., 2012. Biodiesel production catalyzed by Rhizomucor miehei lipase-displaying Pichia pastoris whole cells in an isooctane system. Biochem. Eng. J. 63, 10-14.

Kondo, A., Liu, Y., Furuta, M., Fujita, Y., Matsumoto, T., Fukuda, H., 2000. Preparation of high activity whole cell biocatalyst by permeabilization of recombinant flocculent yeast with alcohol. Enzyme Microb. Technol. 27, 806-811.

Koda, R., Numata, T., Hama, S., Tamalampudi, S., Nakashima, K., Tanaka, T., Ogino, C., Fukuda, H., Kondo, A., 2010. Ethanolysis of rapeseed oil to produce biodiesel fuel catalyzed by Fusarium heterosporum lipase-expressing fungus immobilized whole-cell biocatalysts. J. Mol. Catal. B Enzyme 66, 101-104.

Li, W., Du, W., Liu, D.H., 2007. Rhizopus oryzae IFO 4697 whole cell catalyzed methanolysis of crude and acidified rapeseed oils for biodiesel production in tert-butanol system. Process Biochem. 42, 1481-1485.

Li, A.T., Ngo, T.P.N., Yan, J.Y., Tian, K.Y., Li, Z., 2012. Whole-cell based solvent-free system for one-pot production of biodiesel from waste grease. Bioresour. Technol. 114, 725-729.

Lam, M.K., Lee, K.T., Mohamed, A.R., 2010. Homogeneous, heterogeneous and enzymatic catalysis for transesterification of high free fatty acid oil (waste cooking oil) to biodiesel: a review. Biotechnol. Adv. 28, 500-518.

Matsumoto, T., Fukuda, H., Ueda, M., Tanaka, A., Kondo, A., 2002. Construction of yeast strains with high cell surface lipase activity by using novel display systems based on the Flo1p flocculation functional domain. Appl. Environ. Microbiol. 68, 4517-4522.

Matsumoto, T., Takahashi, S., Kaieda, M., Ueda, M., Tanaka, A., Fukuda, H., Kondo, A. 2001. Yeast whole-cell biocatalyst constructed by intracellular overproduction of Rhizopus oryzae lipase is applicable to biodiesel fuel production. Appl. Microbiol. Biotechnol. 57, 515-520.

Martín, E.H., Otero, C., 2008. Different enzyme requirements for the synthesis of biodiesel: Novozym 435 and Lipozyme TLIM. Bioresour. Technol. 99, 277-286.

Patrick, S.M., Fazenda, M.L., McNeil, B., Harvey, L.M., 2005. Heterologous protein production using the Pichia pastoris expression system. Yeast 22, 249-270.

Rodrigues, R.C., Ortiz, C., Berenguer-Murcia, A., Torres, R., Fernández-Lafuente, R. 2013. Modifying enzyme activity and selectivity by immobilization. Chem. Soc. Rev. 42, 6290-6307.

Takaya, T., Koda, R., Adachi, D., Nakashima, K., Wada, J., Bogaki, T., Ogino, C., Kondo A., 2011. Highly efficient biodiesel production by a whole-cell biocatalyst employing a system with high lipase expression in Aspergillus oryzae. Appl Microbiol. Biotechnol. 90, 1171-1177.

Tan, T.W., Lu, J.K., Nie, K.L., Deng, L., Wang, F., 2010. Biodiesel production with immobilized lipase: a review. Biotechnol. Adv. 28, 628-634.

Verma, M.L., Barrow, C.J., Puri, M., 2013. Nanobiotechnology as a novel paradigm for enzyme immobilisation and stabilisation with potential applications in biodiesel production. Appl. Microbiol. Biotechnol. 97, 23-39.

Xiao, M., Qi, C., Obbard, J.P., 2011. Biodiesel production using Aspergillus niger as a whole cell biocatalyst in a packed-bed reactor. GCB Bioenergy 3, 293-298.

Yan, J.Y., Yang, J.K., Xu, L., Yan, Y.J., 2007. Gene cloning, overexpression and characterization of a novel organic solvent tolerant and thermostable lipase from Galactomyces geotrichum Y05. J. Mol. Catal. B Enzym. 49, 28-35.

Yan, J.Y., Yan, Y.J., Liu, S.X., Hu, J., Wang, G.L., 2011. Preparation of cross-linked lipase-coated micro-crystals for biodiesel production from waste cooking oil. Bioresour. Technol. 102, 4755-4758.

Yan, J.Y., Li, A.T., Xu, Y., Ngo, T.P.N., Phua, S.C., Li, Z., 2012. Efficient production of biodiesel from waste grease: one-pot esterification and transesterification with tandem lipases. Bioresour. Technol. 2012 (123), 332-337. 